\title{
Impact of Immunoglobulin E and Airway Obstruction on Bronchiectasis
}

\author{
Wafaa Ali Hassan ${ }^{1}$, Ibrahiem Shalan ${ }^{2}$, Mohammed Khalifa ${ }^{2}$ \\ ${ }^{1}$ Chest Department, Assiut University, Assiut, Egypt \\ ${ }^{2}$ Chest Department, Al-Azhar University, Assiut, Egypt \\ Email: "wafaagadallah@yahoo.com
}

Received 12 February 2014; revised 12 March 2014; accepted 19 March 2014

Copyright (C) 2014 by authors and Scientific Research Publishing Inc.

This work is licensed under the Creative Commons Attribution International License (CC BY). http://creativecommons.org/licenses/by/4.0/

(c) (i) Open Access

\begin{abstract}
Introduction: Although an increased prevalence of airway obstruction, bronchial hyperreactivity and allergic diseases such as asthma has been associated with bronchiectasis, studies investigating role of atopy in bronchiectasis are few and controversial. We have therefore studied IgE level and reversible airways obstruction in bronchiectasis which have not previously been evaluated in bronchiectasis. Patients and Methods: This study was conducted at Department of Chest Diseases of Al-Azhar University, Assiut, Egypt from January 2012 to December 2013, all consecutive patients with bronchiectasis admitted to the department were enrolled to the study. Serum IgE, pulmonary function tests (PFT) and high resolution computerized tomography (HRCT) were done to all cases. Results: Patients with high IgE $(32 / 50)$ had longer disease duration and frequent history of allergic diseases. They also had significantly worse $F_{E V}(49.38 \pm 12.65 ; p=0.041)$ and FEV $_{1} /$ FVC $(60.89 \pm 13.52, p=0.015)$ values. Mean HRCT score was significantly higher in patients with high IgE than in patients with normal $(18 / 50)$ IgE $(23.6 \pm 10.1$ and $7.83 \pm 2.43$ respectively). IgE showed positive correlation $(r=0.266, p=0.015)$ with HRCT scores. Furthermore, the mean increase in $\mathrm{FEV}_{1}$ after inhalation of salbutamol was significantly greater $(p=0.002)$ in high IgE patients. Conclusions: In conclusion, IgE level is significantly high in bronchiectasis and it may lead to worse pulmonary function and more HRCT extent. Appreciable reversible airways obstruction should be sought in all cases of bronchiectasis and treated appropriately.
\end{abstract}

\section{Keywords}

Atopy, Bronchiectasis, IgE

\footnotetext{
${ }^{*}$ Corresponding author.
} 


\section{Introduction}

Although marked as an "orphan disease" in developed countries, bronchiectasis is not uncommon in developing countries with significant morbidity and mortality [1]. The underlying mechanism can be detected in only $40 \%$ of patients [2] and only a minority of patients benefit from specific treatment. The common symptoms of patients with bronchiectasis are cough with sputum and dyspnoea. The former symptoms are usually well controlled with antibiotics and postural drainage. Dyspnoea varies in severity and is often associated with wheezing, which may simulate asthma [3]. Some authors suggest that atopy is genetically an intrinsic part of bronchiectasis, while others propose that it is a consequence of prolonged, excessive stimulation of the immune system by chronic infection. Bronchiectasis, a condition where pulmonary pathological changes are in many respects similar to those of cystic fibrosis, is lacking also in literature investigating its relation to atopy [4].

Although an increased prevalence of airway obstruction, bronchial hyperreactivity and allergic diseases such as asthma has been associated with bronchiectasis [5], studies investigating role of atopy in bronchiectasis are few and controversial. We have therefore studied IgE level and reversible airways obstruction in bronchiectasis and its relation to pulmonary function tests, which have not previously been evaluated in bronchiectasis.

\section{Patients and Methods}

This study was conducted at Department of chest diseases of Al-Azhar University, Assuit, Egypt from January 2012 to December 2013. All consecutive patients with bronchiectasis admitted to the department were enrolled to the study. Patients with any known cause of bronchiectasis including established diagnosis of asthma and allergic bronchopulmonary aspergillosis, previous tuberculosis, autoimmune and collagen-vascular diseases were excluded. Finally 50 patients with bronchiectasis without any known etiology were included. Patients' characteristics including age, sex, smoking history, disease duration, history of familial atopy, childhood and current allergic disease were recorded.

Patients were divided into two groups of 32 (study group) and 18 patients (controls) respectively according to IgE level (raised total serum IgE of greater than $200 \mathrm{IU} / \mathrm{ml}$ ) [6]. No patients had evidence of colonization with A fumigatus, either from sputum culture, specific IgE or precipitin tests. Eighteen bronchiectasis subjects who had normal IgE served as controls. All subjects answered a respiratory questionnaire, documenting family history of chest disease, smoking habits, and current symptoms such as cough, sputum quality and volume, haemoptysis, and dyspnoea. Additionally, duration of symptoms, precipitating illness, concurrent or past illness, and current treatment were recorded. Each subject completed an atopy questionnaire, recording personal or family history of asthma, wheeze, eczema, urticaria, allergic rhinitis, angioneurotic oedema, contact dermatitis, and drug allergy. An informed consent was obtained from all study subjects. The study was approved by the local ethics committee of Al-Azhar University. Serum IgE was measured by radioimmunoassay. Blood eosinophil count was measured by the counting chamber method [7].

\section{Diagnostic Criteria and HRCT Scoring}

In all patients, HRCT scans with $1 \mathrm{~mm}$ collimation at $10 \mathrm{~mm}$ intervals were obtained through the thorax at end inspiration and they were interpreted by two radiologists who were blinded to clinical history and chest $\mathrm{x}$-ray findings. Criteria for the diagnosis of bronchiectasis utilizing HRCT included the following: 1) dilatation of bronchi as determined by an increased bronchial/adjacent pulmonary artery ratio (ratio $>1$ ) when imaged in cross section (signet-ring sign), 2) parallel bronchial walls when seen in longitudinal section (tram sign), and 3) demonstration of bronchi in the peripheral third of the lung [8]. Bronchiectasis was scored as previously described using the modified Bhalla scoring system [9]. This score has been validated in adult and pediatric patients with bronchiectasis and assigns a value to each lobe and the lingula as follows: bronchiectasis extent (0 3 ), bronchial wall dilatation $(0-3)$ and thickness $(0-3)$, presence of mucus in large $(0-1)$ and small airways $(0$ $-1)$, air trapping $(0-4)$, atelectasis $(0-1)$ and consolidation $(0-1)$ resulting in a worst possible score of 16 . The higher HRCT score represented the more extended and severe bronchiectasis.

\section{Spirometry}

Lung function measurements were performed using a spirometer (Sensormedics, Germany) according to the standardized procedures of the European Respiratory Society [10]. Volume calibration of the spirometer was 
done before each measurement. The forced vital capacity (FVC) and forced expiratory volume in one second $\left(\mathrm{FEV}_{1}\right)$ were taken as the highest readings obtained from at least three satisfactory forced expiratory maneuvers. The participants' baseline lung function was compared with the reference values and expressed as percent of the predicted values.

\section{Statistical Analysis}

SPSS (SPSS for Windows, SPSS Inc., Chicago, IL, USA) statistical package were used for statistical analyses. Descriptive statistics were shown as mean \pm S.D. Univariate analysis was performed using chi-square test for proportion of atopy, sex differences in the study and control groups. To compare parametric values of the groups including age, disease duration, mean HRCT and atopy scores and lung function parameters, Student's $t$-test was used. Correlation of the atopy score with lung function parameters and HRCT score was investigated by Pearson correlation test. A p value less than 0.05 was considered statistically significant.

\section{Results}

Demographic characteristics of both groups did not show a significant difference (Table 1). Smoking habit did not differ significantly between them. The main symptoms were chronic productive cough, which was present in all patients; dyspnoea on exertion, present in 23 (46\%); and haemoptysis, which was reported in 8 (16\%). Lung auscultation identified crepitations in 16 patients (32\%) and 19 (38\%) had finger clubbing. High IgE level was found in 32 of our patients (64\%), whereas 18 patients had normal level (36\%). There were significant differences between the groups in in mean serum IgE concentrations (264 U/ml; versus $47 \mathrm{U} / \mathrm{ml}$ ). High IgE patients had longer disease duration, frequent history of familial atopy, childhood and current allergic disease than controls (Table 2). They had also significantly worse $\mathrm{FEV}_{1}(49.38 \pm 12.65 ; \mathrm{p}=0.041)$ and $\mathrm{FEV}_{1} / \mathrm{FVC}(60.89 \pm$ 13.52; $\mathrm{p}=0.015$ ) values. The extent of the disease on HRCT varied from a single lobe affected in four patients

Table 1. Patient characteristics.

\begin{tabular}{|c|c|c|c|c|c|}
\hline & \multicolumn{2}{|c|}{ Normal IgE $(n=18)$} & \multicolumn{2}{|c|}{ High IgE $(n=32)$} & P-value \\
\hline Male & 9 & 37.5 & 15 & 62.5 & 0.832 \\
\hline Female & 9 & 34.6 & 17 & 65.4 & \\
\hline Age: Mean \pm SD (Range) & \multicolumn{2}{|c|}{$49.22 \pm 7.77$} & \multicolumn{2}{|c|}{$45.09 \pm 14.88$} & 0.280 \\
\hline \multicolumn{6}{|l|}{ Smoking: } \\
\hline Smoker & 7 & 38.9 & 11 & 61.1 & \multirow{3}{*}{0.129} \\
\hline Non-smoker & 9 & 30.0 & 21 & 70.0 & \\
\hline Ex-smoker & 2 & 100.0 & 0 & 0.0 & \\
\hline
\end{tabular}

Table 2. Allergic history and duration of bronchiectasis in both groups.

\begin{tabular}{ccc}
\hline & Normal IgE (n= 18) & High IgE (n = 32) \\
\cline { 2 - 3 } Childhood allergy & NO (\%) & NO (\%) \\
Yes & $2(11 \%)$ & $8(25 \%)$ \\
No & $16(89 \%)$ & $24(75 \%)$ \\
Familial allergy & & $10(31 \%)$ \\
Yes & $1(5 \%)$ & $22(69 \%)$ \\
No & $17(95 \%)$ & $12(37 \%)$ \\
Current allergy & & $20(63 \%)$ \\
Yes & $3(16 \%)$ & 0.003 \\
No & $13(84 \%)$ & $5.95 \pm 7.33$ \\
Mean \pm SD & & $3(0.3-40)$ \\
Median (Range) & $3.74 \pm 9.56$ & 0.006 \\
\hline
\end{tabular}


in control group to all lobes in 15 patients in study group. Mean HRCT score was significantly higher in the study group $(23.6 \pm 10.1)$ than in controls $(7.83 \pm 2.43)$ (Table 3). HRCT scores and IgE values (Figure 1) negatively correlated with $\mathrm{FEV}_{1}$ and $\mathrm{FEV}_{1} / \mathrm{FVC}$ (Table 4). IgE showed positive correlation $(\mathrm{r}=0.266, \mathrm{p}=0.015)$ with HRCT scores (Figure 2). Furthermore, the mean increase in $\mathrm{FEV}_{\mathrm{I}}$ after inhalation of salbutamol was significantly greater $(\mathrm{p}=0.002)$ in the study patients than in controls. Similarly, the mean $\mathrm{FEV}_{1} / \mathrm{FVC}$ was lower and showed a significantly greater $(p=0.009)$ improvement after inhalation of salbutamol. Finally, the FVC showed significantly greater $(\mathrm{p}=0.007)$ improvement in those with high IgE level (study group).

\section{Discussion}

Bronchiectasis is a disease that no cause can be defined in about $40 \%$ of the cases [11]. It is characterized generally by bronchial obstruction and hyperreactivity of which the mechanisms, however, are not well understood [12] [13]. It has been suggested that mucosal edema, glandular hyperplasia and excessive airway collapse in expiration might result in bronchial obstruction [14]. Association of atopy and allergic diseases such as asthma and alteration of bronchial smooth muscle and autonomic neural regulation due to increased access to toxins through infected or inflamed bronchial mucosa could cause bronchial hyperreactivity [15]. The reported prevalence of
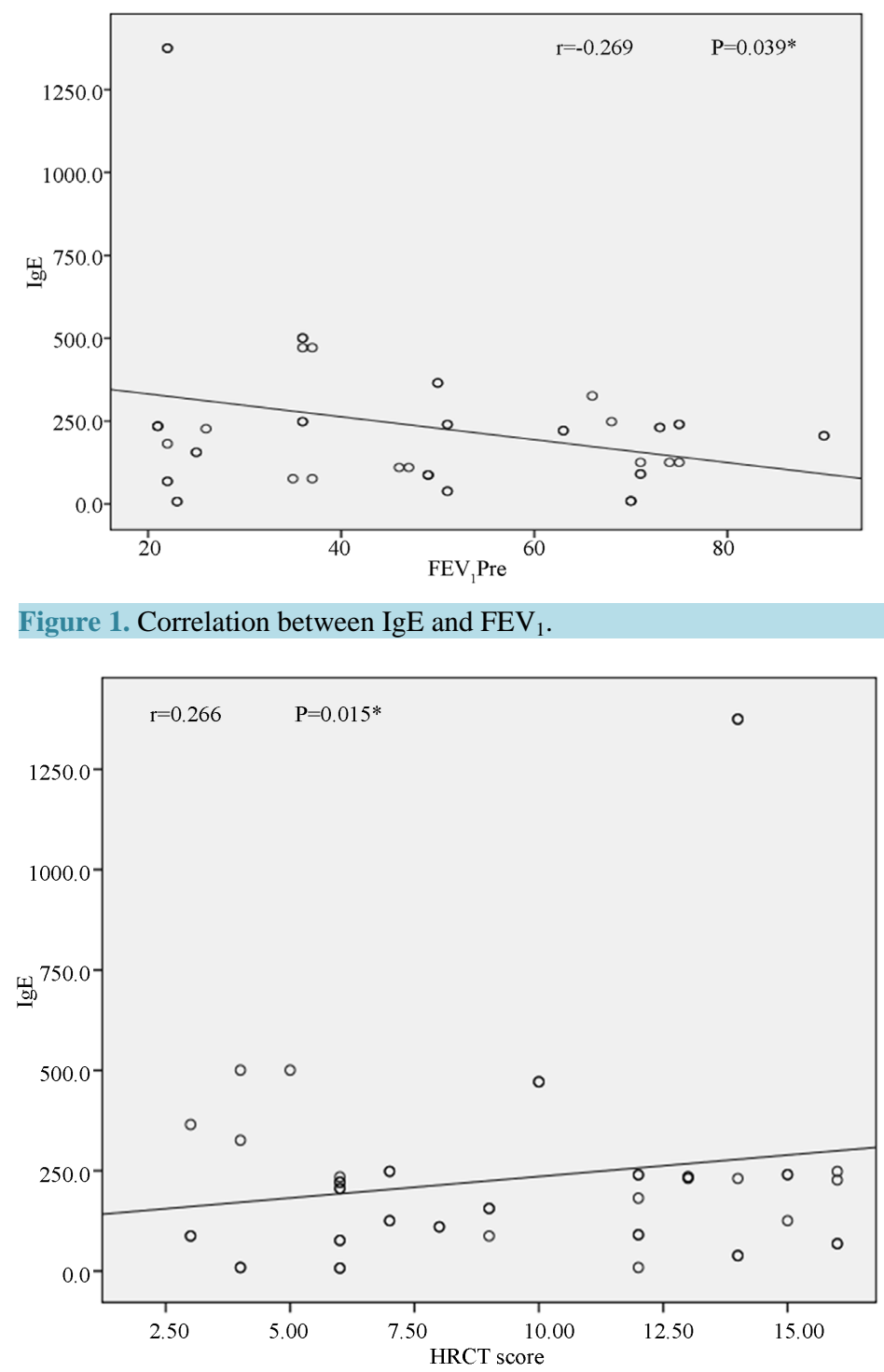

Figure 2. Correlation between IgE and HRCT score. 
Table 3. Pulmonary function tests and HRCT score in the both groups.

\begin{tabular}{cccc}
\hline & Normal IgE $(\mathbf{n}=\mathbf{1 8})$ & High IgE $(\mathbf{n}=\mathbf{1 8})$ & P-value \\
\cline { 2 - 3 } FEV $_{\mathbf{1}}$ & Mean \pm SD & Mean \pm SD & 0.041 \\
FEV $_{\mathbf{1}}$ FVC & $67.56 \% \pm 17.86$ & $49.38 \% \pm 12.65$ & 0.015 \\
HRCT score & $66.2 \% \pm 7.8 \%$ & $60.89 \% \pm 13.52$ & 0.019 \\
\hline
\end{tabular}

Table 4. Correlation between IgE level, HRCT score and pulmonary function tests in bronchiectasis.

\begin{tabular}{ccccc}
\hline & \multicolumn{2}{c}{ IgE } & \multicolumn{2}{c}{ HRCT score } \\
\cline { 2 - 5 } & r-value & P-value & r-value & P-value \\
FEV 1 & -0.269 & 0.039 & -0.610 & 0.034 \\
FVC & -0.303 & 0.062 & -0.178 & 0.215 \\
FEV 1 FVC & -0.968 & 0.006 & -0.250 & 0.050 \\
\hline
\end{tabular}

atopy in patients with bronchiectasis varies from $30 \%$ to $42 \%$ [16]. The application of wider diagnostic criteria probably explains the higher prevalence of atopy (64\%) in our patients. This study has also demonstrated that atopic patients with bronchiectasis had significantly worse pulmonary functions and higher HRCT score, than non-atopic bronchiectasis. Furthermore IgE was correlated positively with HRCT score and negatively with pulmonary function parameters of $\mathrm{FEV}_{1}$ and $\mathrm{FEV}_{1} / \mathrm{FVC}$. These findings indicate that the more severe atopy results in the worse pulmonary function and the more extended and severe bronchiectasis. According to our results, atopy may have a role in bronchial obstruction in bronchiectasis. One may have thought that our results are in conflict with hygiene hypothesis with regard to development of atopy and allergic diseases since recurrent respiratory infections in bronchiectasis would give rise to expect a decreased prevalence of atopy [17]. Some infections that may be associated with both atopy and bronchiectasis such as allergic bronchopulmonary aspergillosis and pertussis [18]. Paunio et al. [19] reported that measles and atopy had occurred more frequently together than expected. Furthermore Bager et al. [17] reported that Danish women with measles during the first year of life were associated with a 3.4-fold increase in the odds ratio of atopy. Other investigations revealed there was no relationship between them due to the biphasic response of natural measles infection [20] [21]. Staphylococcus infection, which is a significant cause of bronchiectasis [22] [23] can be associated with atopy through IL-5 stimulation. The association of bronchiectasis and hepatitis B virus infection that can induce atopy may be another explanation of association of bronchiectasis and atopy [24] due to Th-2 response [25] [26]. High incidence of comorbidity with bacterial infections including sinusitis [27] in atopic subjects may be a contributing factor in pathogenesis of bronchiectasis, suggesting that it might have resulted in higher probability of bronchiectasis [28]. Another study revealed that elevated concentrations of serum amyloid-A in patients with allergic airway disease might reflect presence of a systemic inflammation [29]. We suppose that atopy may be a causative, as well as a coincidence, furthermore atopy might be deteriorating factor for bronchiectasis since IgE level has been positively correlated with HRCT score, in other words, the more atopy is the more extended bronchiectasis will be.

The results of the studies in the literature investigating the prevalence of atopy in bronchiectasis are few in number and conflicting [30]. Varpela et al. [31] found prevalence of atopy in their series of 48 patients with bronchiectasis was $10 \%$. Their study was uncontrolled and diagnosis of bronchiectasis was based on bronchography, which is less sensitive than HRCT used in our study. In another study of Hassan et al. [32], atopy was found in 13 of 24 (54\%) patients with bronchiectasis while Pang et al. [13] and Murphy et al. [28] reported atopy prevalence as $25 \%$ and $30 \%$, respectively. The different results of other studies could be attributed to methodological differences. Although findings of Hassan et al. [32] were similar to our results, their study was uncontrolled. Our study population was larger and significant correlations of atopy score with HRCT score and lung function tests have been reported.

We have shown a significant reversibility of airway obstruction after inhalation of salbutamol in atopic patients with bronchiectasis. Previous studies on bronchodilators in bronchiectasis have been infrequent and old. 
Cherniak and Carton [33] showed negligible changes in $\mathrm{FEV}_{1}$, FVC, or RV after inhalation of bronchodilators, while others [34] showed no significant change in inspiratory or expiratory pulmonary resistance or dynamic compliance. According to our results we would suggest that all patients with bronchiectasis should have an assessment of the reversibility of airways obstruction by beta adrenergic agonists, before its addition in treatment.

In conclusion, atopy is significantly frequent in bronchiectasis and it may lead to worse pulmonary function and more HRCT extent. Clinicians should be aware of this issue, however exact relationship with these entities, remains to be investigated by means of other larger sample size studies.

\section{References}

[1] Barker, A.F. and Bardana Jr., E.J. (1988) Bronchiectasis: Update of an Orphan Disease. American Review of Respiratory Disease, 137, 969-978. http://dx.doi.org/10.1164/ajrccm/137.4.969

[2] Hilton, A.M. and Doyle, L. (1978) Immunological Abnormalities in Bronchiectasis with Chronic Bronchial Suppuration. British Journal of Diseases of the Chest, 72, 207-216. http://dx.doi.org/10.1016/0007-0971(78)90043-8

[3] Varpela, E., Laitinen, L.A., Keskinen, H. and Korhola, O. (1978) Asthma, Allery and Bronchial Hyperreactivity to Histamine in Patients with Bronchiectasis. Clinical \& Experimental Allergy, 8, 273-280. http://dx.doi.org/10.1111/j.1365-2222.1978.tb03224.x

[4] Tobin, M.J., Maguire, O., Reen, D., Tempany, E. and Fitzgerald, M.X. (1980) Atopy and Bronchial Reactivity in Older Patients with Cystic Fibrosis. Thorax, 36, 807-813. http://dx.doi.org/10.1136/thx.35.11.807

[5] Al-Mousawi, M.S.H., Lovel, H., Behbehani, N., Arifhodzic, N., Woodcock, A. and Custovic, A. (2004) Asthma and Sensitization in a Community with Low Indoor Allergen Levels and Low Pet-Keeping Frequency. The Journal of Allergy and Clinical Immunology, 114, 1389-1394. http://dx.doi.org/10.1016/j.jaci.2004.09.005

[6] Nogrady, S.G., Evans, W. and Davies, B.H. (1978) Reversibility of Airways Obstruction in Bronchiectasis. Thorax, 33, 635-637. http://dx.doi.org/10.1136/thx.33.5.635

[7] BüyükÖztürk, S., Gelincik, A.A., Genç, S., Kocak, H., Öneriyidogan, Y., Erden, S., Dal, M. and Çolakoglu, B. (2004) Acute Phase Reactants in Allergic Airway Disease. The Tohoku Journal of Experimental Medicine, 204, 209-213. http://dx.doi.org/10.1620/tjem.204.209

[8] Pifferi, M., Caramella D., Bulleri, A., Baldi, S., Peroni, D., Pietrobelli A. and Boner, A.L. (2004) Bronchiectasis: Correlation of HRCT, Ventilation and Perfusion Scintigraphy, and Pulmonary Function Testing. Pediatric Pulmonology, 38, 298-303. http://dx.doi.org/10.1002/ppul.20110

[9] Bhalla, M., Turcois, N., Aponte, V., Jenkins, M., Leitman, B.S., McCauley, D.I. and Naidich, D.P. (1991) Cystic Fibrosis: Scoring System with Thin Section CT. Radiology, 179, 783-788.

[10] Pellegrion, R., Viegi, G., Enright, P., et al. (2005) Interpretation of Lung Function Test. European Respiratory Journal, 26, 948-968. http://dx.doi.org/10.1183/09031936.05.00035205

[11] Tsang, K.W. and Tipoe, G.L. (2004) Bronchiectasis: Not an Orphan Disease in the East. The International Journal of Tuberculosis and Lung Disease, 8, 691-702.

[12] Twiss, J., Metcalfe, R., Edwards, E. and Byrnes, C. (2005) New Zealand National Incidence of Bronchiectasis “Too High” for a Developed Country. Archives of Disease in Childhood, 90, 737-740. http://dx.doi.org/10.1136/adc.2004.066472

[13] Pang, J., Chan, H.S. and Sung, J.Y. (1989) Prevalence of Asthma, Atopy, and Bronchial Hyperreactivity in Bronchiectasis: A Controlled Study. Thorax, 44, 948-951. http://dx.doi.org/10.1136/thx.44.11.948

[14] Ip, M., Lam, M.W., So, S.Y., Liong, E., Chan, C.Y. and Tse, K.M. (1991) Analysis of Factors Associated with Bronchial Hyperreactivity to Methacholine in Bronchiectasis. Lung, 169, 43-51. http://dx.doi.org/10.1007/BF02714140

[15] Bodner, C., Godden, G. and Seaton, A. (1998) Family Size, Childhood Infections and Atopic Diseases. Thorax, 53, 28-32. http://dx.doi.org/10.1136/thx.53.1.28

[16] Ip, M.S.M., So, S.Y., Lam, W.K. and Liong, E. (1992) High Prevalence of Asthma in Patients with Bronchiectasis in Hong Kong. European Respiratory Journal, 5, 418-423.

[17] Bager, P., Westergaard, T., Rostgaard, K., Hjalgrim, H. and Melbye, M. (2002) Age at Childhood Infections and Risk of Atopy. Thorax, 57, 379-382. http://dx.doi.org/10.1136/thorax.57.5.379

[18] Von Mutius, E. (2001) Infection: Friend or Foe in the Development of Atopy and Asthma? The Epidemiological Evidence. European Respiratory Journal, 18, 872-881. http://dx.doi.org/10.1183/09031936.01.00268401

[19] Paunio, M., Heinonen, O.P., Virtanen, M., Leinikki, P., Patja, A. and Peltola, H. (2000) Measles History and Atopic Diseases: A Population-Based Cross-Sectional Study. JAMA, 283, 343-346. http://dx.doi.org/10.1001/jama.283.3.343

[20] Farooqi, I.S. and Hopkin, J.M. (1998) Early Childhood Infection and Atopic Disorder. Thorax, 53, 927-932. 
http://dx.doi.org/10.1136/thx.53.11.927

[21] Corne, J.M., Lau, L., Scott, S.J., Davies, R., Johnston, S.L. and Howart, P.H. (2001) The Relationship between Atopic Status and IL-10 Nasal Lavage Levels in the Acute and Persistent Inflammatory Response to Upper Respiratory Tract Infection. American Journal of Respiratory and Critical Care Medicine, 163, 1101-1107. http://dx.doi.org/10.1164/ajrccm.163.5.9902047

[22] Heaton, T., Mallon, D., Venaille, T. and Holt, P. (2003) Staphylococcal Enterotoxin Induced IL-5 Stimulation as a Cofactor in the Pathogenesis of Atopic Disease: The Hygiene Hypothesis in Reverse? Allergy, 58, 252-256. http://dx.doi.org/10.1034/j.1398-9995.2003.00088.x

[23] Mucha, S.M. and Baroody, F.M. (2003) Relationships between Atopy and Bacterial Infections. Current Allergy and Asthma Reports, 3, 232-237. http://dx.doi.org/10.1007/s11882-003-0045-2

[24] Kocabas, C.N. (2001) Do Hepatitis B Virus Carriers Develop Atopic Diseases? Allergy, 56, 1100-1101. http://dx.doi.org/10.1034/j.1398-9995.2001.00377.x

[25] Ji, W., Wang, H.F. and Feng, C.Q. (2001) Activation-Induced Cell Death in Peripheral Blood Mononuclear Cells (PBMCs) from Patients with Chronic Hepatitis B May Be Related to Abnormal Production of Interleukin 12 and 10. Journal of Viral Hepatitis, 8, 30-33. http://dx.doi.org/10.1046/j.1365-2893.2001.00251.X

[26] Naumov, N.V. and Rossol, S. (1997) Studies of Interleukin-12 in Chronic Hepatitis B Virus Infection. Journal of Viral Hepatitis, 4, 87-91. http://dx.doi.org/10.1111/j.1365-2893.1997.tb00185.x

[27] Pasteur, M.C., Helliwell, S.M., Houghton, S.J., Webb, S.C., Foweraker, J.E., Coulden, R.A., Flower, C.D., Bilton, D. and Keogan, M.T. (2000) An Investigation into Causative Factors in Patients with Bronchiectasis. American Journal of Respiratory and Critical Care Medicine, 162, 1277-1284. http://dx.doi.org/10.1164/ajrccm.162.4.9906120

[28] Murphy, M.B., Reen, D.J. and Fitzgerald, M.X. (1984) Atopy, Immunological Changes, and Respiratory Function in Bronchiectasis. Thorax, 39, 179-184. http://dx.doi.org/10.1136/thx.39.3.179

[29] Cohen, M. and Sahn, S.A. (1999) Bronchiectasis in Systemic Diseases. Chest, 116, 1063-1074. http://dx.doi.org/10.1378/chest.116.4.1063

[30] Roberts, H.R., Wells, A.U., Milne, D.G., Rubens, M.B., Kolbe, J., Cole, P.J. and Hansell, D.M. (2000) Airflow Obstruction in Bronchiectasis: Correlation between Computed Tomography Features and Pulmonary Function Tests. Thorax, 55, 198-204. http://dx.doi.org/10.1136/thorax.55.3.198

[31] Varpela, E., Laitinen, L.A., Keskinen, H. and Korhola, O. (1978) Asthma, Allergy and Bronchial Hyper-Reactivity to Histamine in Patients with Bronchiectasis. Clinical Experimental Allergy, 8, 273-280. http://dx.doi.org/10.1111/j.1365-2222.1978.tb03224.X

[32] Hassan, J.A., Saadiah, S., Roslan, H. and Zainudin, B.M.Z. (1999) Bronchodilator Response to Inhaled Beta-2 Agonist and Anticholinergic Drugs in Patients with Bronchiectasis. Respirology, 4, 423-426. http://dx.doi.org/10.1046/j.1440-1843.1999.00215.x

[33] Cherniak, N.S. and Carton, R.W. (1966) Factors Associated with Respiratory Insufficiency in Bronchiectasis. American Journal of Medicine, 41, 562-571. http://dx.doi.org/10.1016/0002-9343(66)90218-X

[34] Pande, J.N., Jain, B.P., Gupta, R.G. and Guleria, J.S. (1971) Pulmonary Ventilation and Gas Exchange in Bronchiectasis. Thorax, 26, 727-733. http://dx.doi.org/10.1136/thx.26.6.727 